\title{
Psychological Dissection of Homicidal Behavior in Schizophrenia: Focus on Frustration Tolerance, a Pilot Study
}

\author{
Petar Marinov ${ }^{1 *}$, Kaloyan Kukov², Anka Petrova ${ }^{1}$, Pavlina Petkova ${ }^{3}$, Vladimir Velinov ${ }^{3}$ and Sylvia \\ Ralovska $^{1}$
}

${ }^{1}$ Mental Health Center, Bulgaria

${ }^{2}$ Medical University, Bulgaria

${ }^{3}$ Varna Free University, Bulgaria

*Corresponding author: Petar Marinov, Mental Health Center "Prof. Nikola

Schipkowensky" LTD, 59 Exarch Jossif str., 1000 Sofia, Bulgaria.

Keywords: Schizophrenia; Homicide; Frustration tolerance

\section{Background}

Emotional dysregulation in schizophrenia results from a pathological transformation of emotions. Rosenzweig frustration test (RFT) is a projective test that discriminates whether an individual reacts with a response of tolerance or intolerance under a frustrating situation. The test comprises 24 pictures that relate to 21 specific categories of assessment of coping strategies in frustration situations. To our knowledge, there is no study on frustration tolerance comparing schizophrenia with or without homicide in the current literature. Our study investigated this area.

\section{Materials and Methods}

Two groups of patients with schizophrenia were compared. First group consisted of patients with paranoid schizophrenia who had committed homicide 1 to 3 months prior to assessment $(n=43$, male 35, female 8). Second group included patients with paranoid schizophrenia without homicide $(n=40$, male 30 , female 10$)$. There were no statistically significant differences between groups in terms of age and gender (Table 1).

Table 1: Age.

\begin{tabular}{|c|c|c|c|c|c|}
\hline Group & $\mathbf{N}$ & $\bar{X}^{*}$ & SD & Min & Max \\
\hline $\begin{array}{c}\text { Schizophrenia with } \\
\text { homicide }\end{array}$ & 43 & $35,70 \mathrm{a}$ & 10,92 & 17 & 62 \\
\hline $\begin{array}{c}\text { Schizophrenia without } \\
\text { homicide }\end{array}$ & 40 & $37,68 \mathrm{a}$ & 12,58 & 17 & 61 \\
\hline
\end{tabular}

*No significant differences $(p>0.05)$
Rosenzweig P-F test (Bulgarian version) was used to assess parameters of frustration tolerance and aggression $(1,2)$. Data were analyzed by SPSS v.12.0 (2003), one-way ANOVA (3).

\section{Result}

As presented on Figure 1, extra-punitivity is statistically more prominent in the group of patients with schizophrenia and homicide $(p<0.05)$. This is consistent with paranoid ideation of general environmental threat. Other differences without statistical significance are on categories "frustrating situation" and "intropunitivity towards frustrating situation". So, the situation is more provoking in the group with homicide than one without homicide. Not surprisingly, results for categories "intro-punitivity" and "impunitivity" are higher in the group schizophrenia without homicide, possibly due to better management of violent tendencies.

Figure 2 shows that results on "extra-punitivity toward person" are significantly higher in schizophrenia with homicide group than in schizophrenia without homicide group. Higher levels of hostility against others in the group with homicide are one possible explanation. Similar results were found in the item "total blaming of others", also closely related to hostility. Lower results on categories "intro-punitivity towards person", "impunitivity towards person", "self- inculpation", "collective tendency to self- exculpation" and "collective tendency to exculpation" also might represent that 
homicidal schizophrenia patients show some specific peculiarities. These results might also be explained as a pathological personality change leading to lower ability to cope with blame. Another possible explanation is premorbid personality traits (Figure 1).

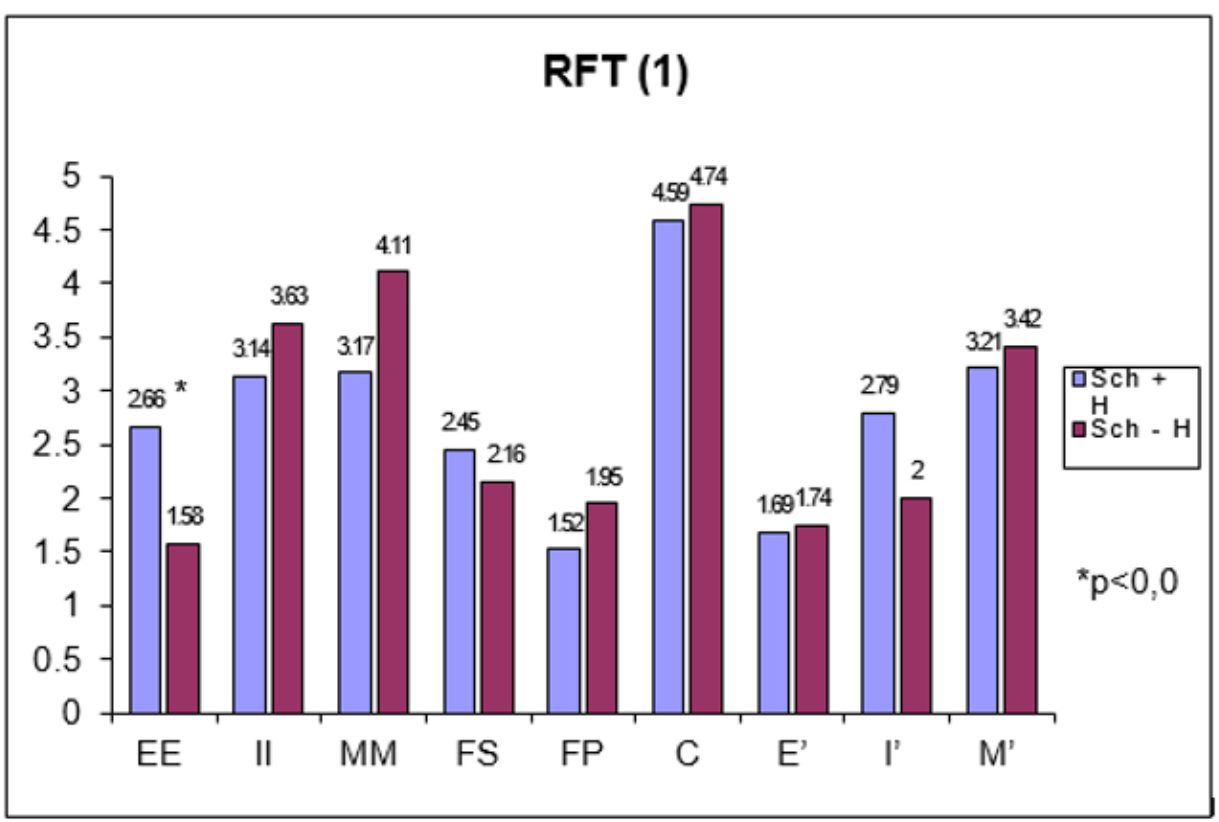

Figure 1: MRFT. Items 1 to 9.

EE - exrtra-punitivity ("the individual tends to blame the external world"); II - intro-punitivity ("the individual tends to blame himself,"); MM - impunitivity (avoidance of aggression); FS - frustrating situation; FP - frustrating person; C - coping with the frustrating situation; E' - extra-punitivity towards frustrating situation; I' - intra-punitivity towards frustrating situation; M' impunitivity towards frustrating situation (Figure 2).

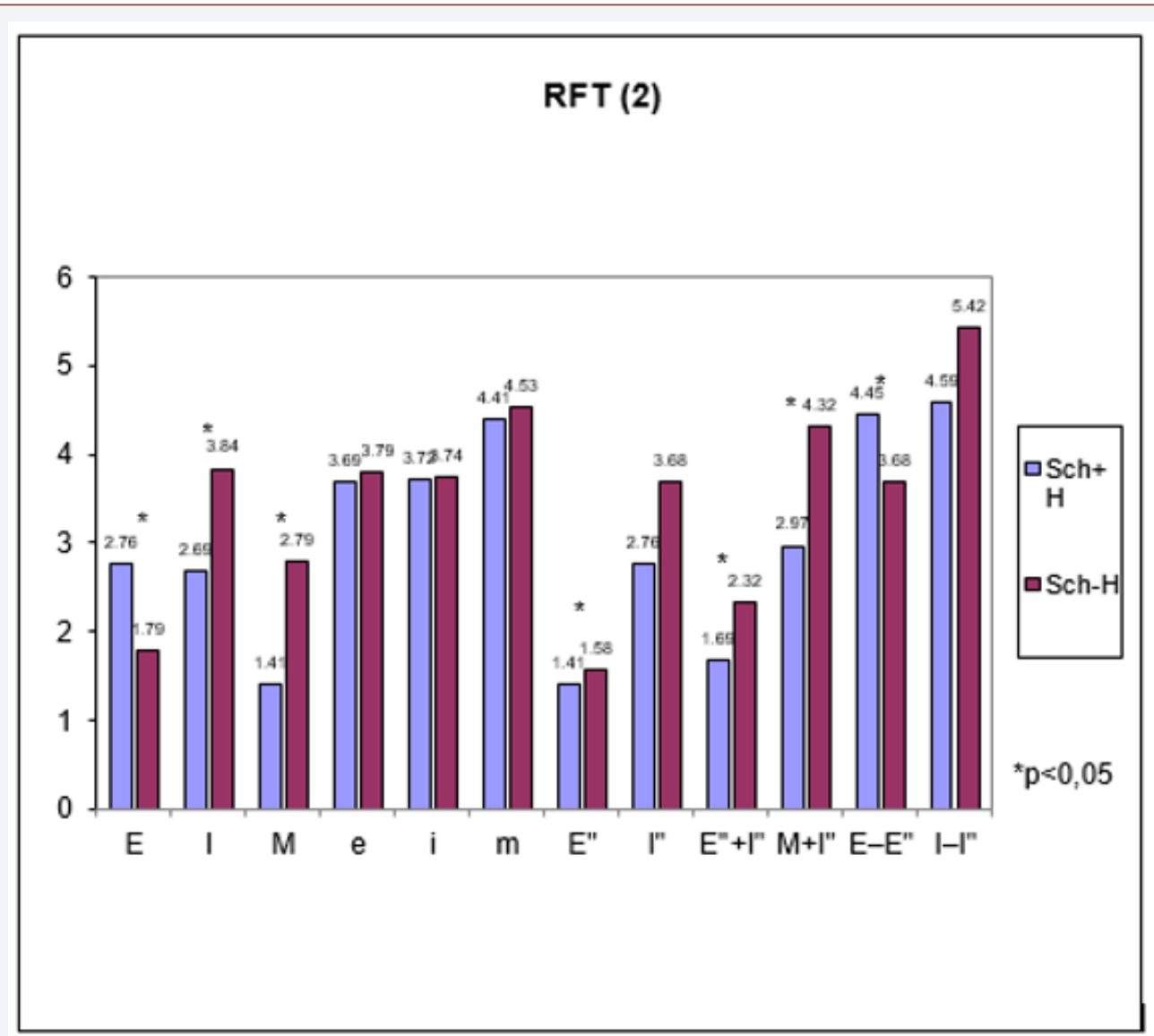

Figure 2: RFT. Items 10 to 21. 
E - extra-punitivity towards person; i - intro-punitivity towards person; M - impunitivity towards person; e - extra-punitivity towards coping with the frustrating situation; i - intro-punitivity towards coping with the frustrating situation; m - impunitivity towards coping with the frustrating situation; E" - blaming others (extra-motivated self- exculpation); I" - self - inculpation (intramotivated); E" + I" - collective tendency to self-exculpation; $\mathrm{M}+\mathrm{I}$ " collective tendency to exculpation; E - E" - total blaming of others; I - I" - total self-blaming.

\section{Conclusion}

The presented study results show some important differences between groups. Impairment of the ability for recognition of emotions (of oneself and of others) is a common pathway of dysregulation of emotions in schizophrenia. Persistence of negative emotions (eg. hostility) as well as their attribution to other people and to external situations is a putative mechanism for psychotic projection. Preservation of premorbid personality structure and better coping strategies can possibly explain a less distorted concept of blame in schizophrenia patients who have not committed homicide.

\section{Acknowledgement}

None.

\section{Conflict of Interest}

No conflict of interest.

\section{References}

1. Rosenzweig S (1963) Validity of the Rosenzweig Picture-Frustration Study with felons and delinquents. Journal of Consulting Psychology 27(6): 535-536.

2. Rauchfleisch U (1971) Neue Interpretationsmöglichkeiten des Rosenzweig Picture-Frustration-Tests durch Verwendung von Indizes. Schweiz Z Psychol 30: 299-311.

3. SPSS Inc. Released (2003) SPSS for Windows, Version 12.0. SPSS Inc, Chicago, USA. 